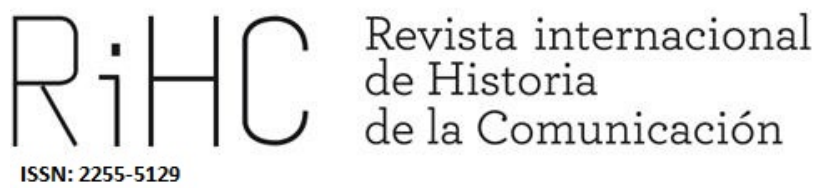

\title{
REPUBLICANOS FEDERALES EN EL PERIODISMO ESPAÑOL DE LA CIUDAD DE MÉXICO DURANTE LA DÉCADA DE 1880
}

\section{Federal Republicans in Spanish journalism in Mexico City during the} $1880 s^{1}$

DOI: http://dx.doi.org/10.12795/RiHC.2019.i12.15

Recibido: $13 / 03 / 20019$

Aceptado: 01/04/2019

Publicado:15/06/2019

María del Mar Gutiérrez Domínguez

El Colegio de México, México

mmgutierrez@colmex.mx

\footnotetext{
${ }^{1}$ Este texto se ha realizado dentro del equipo de investigación HAR2015-64494-R titulado: “La prensa de la emigración española: acción cultural, patriotismo y recreación identitaria. Estudios de caso en Argentina, Cuba, México y Uruguay, 1870-1960".
} 
Resumen: El artículo tiene como objetivo resaltar una característica de la prensa española de la Ciudad de México a finales del siglo XIX: la adscripción republicana federal de varios de los directores de estas publicaciones. Se pondrá atención a las relaciones que mantuvieron estos periodistas entre sí y sus respectivas publicaciones, así como con la colonia española. Además, un aspecto central del análisis es estudiar el vínculo que estos actores políticos establecieron con la sociedad y el gobierno de destino. Así, periodistas que en España habían luchado por la democracia, a favor de una República Federal, arribaban a un México que si bien garantizaba la paz, la estabilidad y el progreso, no se comprometía con muchas de las libertades asociadas al liberalismo. Estos individuos tuvieron una relación desigual tanto con el gobierno de Porfirio Díaz como con los directores de otras publicaciones españolistas. Los periodistas que se estudian en este artículo son José Barbier Roselló, Ramón Elices Montes y José Román Leal.

Palabras clave: colonia española, México, periodismo, I República Española

\begin{abstract}
The article aims to highlight a feature of the Spanish press in Mexico City at the end of the 19th century: the republican federal affiliation of several of the directors of these publications. Attention will be paid to the relations that these journalists maintained with each other and their respective publications, as well as with the Spanish colony. In addition, a central aspect of the analysis is to study the link that these political actors established with society and the destination government. Thus, journalists who in Spain had fought for democracy, in favor of a Federal Republic, came to a Mexico that while guaranteeing peace, stability and progress, did not commit to many of the freedoms associated with liberalism. These individuals had an unequal relationship with both the government of Porfirio Diaz and the directors of other Spanish publications. The journalists who are studied in this article are José Barbier Roselló, Ramón Elices Montes and José Román Leal.
\end{abstract}

Keywords: Spanish colony, Mexico, Journalism, I Republic (Spain)

\title{
Introducción
}

La I República Española (1873-1874) fue resultado de una serie de sucesos políticos y sociales que se originaron como consecuencia del derrocamiento de Isabel II (1868) y que dieron lugar al periodo conocido como Sexenio Democrático (1868-1874), siendo la experiencia republicana la etapa final y colofón de este proceso. Así, tras el efímero reinado de Amadeo de Saboya (1871-1873), las Cortes proclamaron la I República (11 febrero 1873), que se caracterizó por la inestabilidad política ${ }^{2}$ y la heterogeneidad de

\footnotetext{
${ }^{2}$ Tuvo cuatro presidentes en menos de un año, todos del Partido Republicano Federal: Estanislao Figueras (11 febrero-11 junio 1873), Francisco Pi y Margall (11 junio-18 julio 1873), Nicolás Salmerón (18 julio-6 septiembre 1873) y Emilio Castelar (7 septiembre 1873-3 enero 1874).
} 
propuestas, concepciones e ideas existentes dentro del Partido Republicano Federal $(\mathrm{PRF})^{3}$. Esta diversidad se relacionaba con cuestiones doctrinales -unitarios frente a federales, socialistas frente a individualistas-, de procedimiento -acción pacífica, propagandística (reformistas) o sublevación popular, mediante el uso de la violencia y la insurrección armada (revolucionarios) - y enfrentamientos personales (Suárez Cortina, 1986: 3, citado en Rivadulla, 1992: 311).

El golpe de estado de Pavía (3 enero 1874) supuso de facto el fin de la I República aunque continuaría de manera nominal hasta diciembre de ese año- y la formación de un gobierno de concentración bajo la presidencia de Francisco Serrano, del que se excluyó a los republicanos federales. Estos sucesos, sumados a la posterior Restauración Borbónica (1875) marcaron la emigración y el exilio de muchos republicanos. El destino principal fue el norte de Argelia y el sur de Francia, debido a la cercanía geográfica y el hecho de que la militancia republicana más fuerte se había ubicado en el arco del Mediterráneo (Vilar, 2012: 270). Una cantidad menor de estos individuos se dirigieron hacia las naciones hispanoamericanas, donde Argentina fue el mayor país receptor de esta inmigración (Devoto, 2003; Moya, 2004; Biagini, 1995) ${ }^{4}$.

No obstante, el objetivo de este artículo es estudiar a un número menor de exiliados y emigrados que se dirigieron a México. A este respecto, merece la pena señalar que el contingente migratorio español durante este periodo se caracterizó por una escasa afluencia numérica, nunca superior al $0,2 \%$ del total de la población, pese a ser el grupo extranjero más numeroso. Así, en 1877 había 6.400 peninsulares en toda la República, que llegaron a ser casi 30.000 en 1910, lo que representa un aumento promedio de 700 individuos al año. Además, estos españoles destacan por su inserción en sectores económicos que proporcionaban grandes capitales y beneficios, como la industria, el comercio, la banca o las empresas agrícolas, de las que en muchas ocasiones eran propietarios. Sin embargo, el grueso de la población se dedicaba al comercio, en calidad de dependientes, sector en el que era común experimentar un ascenso socioeconómico a lo largo de los años de trabajo. Todo lo anterior ha merecido que la inmigración española en México haya sido calificada como "privilegiada". El asentamiento de estos individuos era fundamentalmente en el área urbana, donde destacan la Ciudad de México (67\%), Puebla (3,56\%) y Veracruz (3,03\%). Respecto a su lugar de origen, más del $50 \%$ provenían de las actuales Cantabria y Asturias, seguidas de País Vasco y Cataluña. Por último, quienes migraban eran en la mayor parte de los casos hombres, jóvenes y solteros (Lida, 1994: 25-51).

Nuestro análisis se enfocará en el estudio de tres individuos -José Barbier Rosselló, Ramón Elices Montes y José Román Leal- que, provenientes de la militancia federalista

\footnotetext{
${ }^{3}$ Primer partido político específicamente republicano, fundado en 1868.

${ }^{4}$ Esto se relaciona con las características generales de la emigración durante este periodo, donde Argentina atrajo el mayor número de emigrantes europeos.
} 
en España, se convirtieron en representantes del periodismo españolista en la capital mexicana, al ser los directores de tres de las principales publicaciones españolas en la Ciudad de México durante este periodo ${ }^{5}$. Lo anterior resulta de gran relevancia, pues la colonia española en la capital mexicana era conocida por sus tendencias monárquicas. Poco después del triunfo de la Revolución de Septiembre (1868), que dio inicio al Sexenio Democrático, el Conde de Casafiel-Encargado de la Legación de los Archivos de España en México ${ }^{6}$ - escribía al gobierno de Madrid que "la gloriosa revolución efectuada en España ha caído como un rayo sobre la mayoría de españoles aquí residentes, que carlistas en su mayor número, la maldicen y anatematizan, en cuantas ocasiones se les presentan"7. Asimismo, una carta anónima, publicada a fines de 1885 en La Voz de España, afirmaba lo siguiente: "En difícil trance me coloca vd., [...] previniéndome que para poder publicar mis cartas en La Voz de España, debo procurar que no tengan un sabor democrático demasiado pronunciado, porque en ese país, aunque regido por instituciones republicanas federales, la colonia española, generalmente, si las acepta no es con fervor ni entusiasmo, al contrario, parece más bien inclinada al monarquismo" ${ }^{8}$. Empero, como indica Daniel Rivadulla Barrientos, un aspecto fundamental de la presencia de estos republicanos federales en América fue su labor en la prensa periódica. Su formación política resultó esencial en una época en que la función prioritaria de la prensa era política (Rivadulla Barrientos, 1992: 351). Una carta remitida por el Sr. Barón de la Barre -Encargado de Negocios de España en México- al Ministerio de Estado, en octubre de 1888 , se quejaba de que las ideas republicanas de varios redactores de los periódicos españoles en México no eran "todo lo favorable que es de desear al Gobierno de S.M. la Reina Regente" ${ }^{9}$.

Estos individuos no fueron los únicos representantes periodísticos de una colonia española que contó con una gran diversidad de publicaciones que se decían sus voceros, lo cual se debe a la enorme heterogeneidad social, política, económica, ideológica y, también, periodística que caracterizó a la colonia española en la Ciudad de México. Así, en las siguientes páginas veremos los debates que estos republicanos federales mantuvieron con los periodistas de tendencias republicanas más centralistas, así como monárquicos. Sin embargo, el presente artículo busca poner el acento en las relaciones

\footnotetext{
${ }^{5}$ En este estudio no se considerarán a los redactores republicanos federales, pues el elevado número de periodistas que, de muy diversas maneras, participaron en las publicaciones españolas -y mexicanas-, así como la dificultad de determinar el perfil ideológico de todos los redactores españoles en estos años, exceden los objetivos del presente trabajo. Además, el contenido de los periódicos era responsabilidad de sus directores, quienes otorgaban -o no- su aval previo antes de publicarse.

${ }^{6}$ Durante el tiempo que no existió representación oficial española en México -entre 1867 y 1871-, el Conde de Casafiel fue el encargado de auspiciar el desarrollo de una política de amistad entre México y España, y responsable de la correspondencia con el gobierno español.

${ }^{7}$ AHN, H 1656 Embajadas-Legaciones Méjico 1869-1879, № 9, 14-1-1869.

8 “Carta de España”, La Voz de España, 9-12-1885.

${ }_{9}^{9}$ AHN, H 1657 Embajadas-Legaciones Méjico 1880-1901, № 76, 14-10-1888.
} 
que estos periodistas federales mantuvieron entre sí y sus respectivas publicaciones, las cuales estuvieron plagadas de enfrentamientos y tensiones políticas y periodísticas que, en parte, replicaban las enemistades que habían caracterizado a la I República. Empero, estas tiranteces no se relacionaban únicamente con el país de origen, pues se vieron afectadas y modificadas por la relación que estos actores políticos mantuvieron con la sociedad y el gobierno de destino.

\section{El exilio republicano en México}

El primer periodista republicano federal del que existe noticia en México -el famoso y polémico Adolfo Llanos y Alcaraz, que radicó en la capital mexicana entre 1873 y 1879no será objeto de atención en las siguientes páginas. Aunque su adscripción al republicanismo federal resulta más que conocida -fue amigo y secretario personal de Nicolás Estévanez (diputado del PRF y ministro de guerra durante la I República)-, sus actividades en México no estuvieron marcadas por su vinculación a esta corriente ideológica, sino por un españolismo fuertemente combativo $y$, en ocasiones, un acercamiento a los carlistas. Esto último con motivo de la visita a México del aspirante al trono, Don Carlos. La investigadora Lilia Vieyra ha explicado de manera excelente las motivaciones de Llanos para actuar de esta manera, relacionadas con las tensiones entre distintos grupos de la colectividad y con la Legación Española (Vieyra, 2014).

Durante el resto de la década de 1870 no destaca en el periodismo españolista de la capital mexicana ningún individuo más vinculado con la República Federal, para ello habrá que esperar hasta abril de 1880, cuando José Barbier Rosselló adquirió la propiedad de La Voz de España (1879-1888) y comenzó a ser su director, cargo que ostentaría durante los siguientes ocho años, hasta la desaparición de la publicación. A modo de antecedente, es necesario mencionar que José Barbier sustituía al anterior propietario y director -Enrique Muñiz-, quien al asumir este cargo -1879- se había posicionado dentro del enfrentamiento en que andaba sumida la colonia española de la Ciudad de México desde años atrás. Éste se relacionaba con las tensiones existentes entre el grupo reunido en torno al Casino Español y la Legación de España en México. El primer grupo estaba formado por empresarios e industriales españoles interesados en el desarrollo de sus negocios en México, quienes tenían como su vocero frente a la opinión pública a La Colonia Española (1873-1879) (Herrera Lasso, 1998; Gutiérrez Hernández, 2014; Pi-Suñer Llorens, 1994: 80) ${ }^{10}$. Por su parte, la representación oficial

\footnotetext{
${ }^{10}$ Los individuos reunidos en torno al Casino Español gozaban de un importante capital y posición social. El origen de sus fortunas era el comercio, que desde el virreinato estaba en manos de peninsulares, pero fueron sus actividades como prestamistas del gobierno y especuladores con la deuda pública lo que les permitió desarrollar una gran fortuna. A cambio de sus préstamos obtuvieron concesiones para la
} 
española se había quedado sin un órgano de prensa que le fuese favorable tras la desaparición de La Iberia (1867-1876), ya que este periódico había representado de manera oficiosa los intereses gubernamentales en el país ${ }^{11}$. La fundación de La Voz de España se produjo tres años después de la desaparición de La lberia y poco después del fin de La Colonia Española. Se trató de una campaña de prensa emprendida por la Legación para que la opinión pública española de la capital mexicana fuese favorable a su autoridad.

En gran parte, el enfrentamiento entre el Casino Español y la Legación Española se relacionaba con que en el primero existían grupos de presión que deseaban que se realizase una defensa enérgica de sus intereses económicos frente al gobierno mexicano. Estos se relacionaban con la exigencia del pago de la "deuda española" (PiSuñer Llorens, 2006) ${ }^{12}$, así como otras demandas sustentadas en desacuerdos en materia de política económica ${ }^{13}$. No obstante, las instrucciones del gobierno de España a Emilio de Muruaga -Ministro de España en México entre 1875 y 1882- fueron las de fortalecer los lazos de amistad con México -recientemente restablecidos, tras la suspensión de relaciones diplomáticas en 1867- y posponer la exigencia de la "deuda española" y otras reivindicaciones hasta que las relaciones fueran más estables (Pi-Suñer Llorens y Sánchez Andrés, 2001: 230-232). Como se puede observar, lo anterior entrañaba una lucha de poder y representación entre la Legación y el Casino Español,

explotación de minas, el estanco de tabaco, la casa de moneda, la construcción de caminos, etc. Con el tiempo, estos individuos llegarían a convertirse en ricos propietarios, industriales, banqueros y empresarios. En el Casino Español fortalecían sus lazos económicos mediante el contacto con otros grandes hombres de negocios y llevaban a cabo una sociabilidad restringida con otros miembros de su mismo nivel socioeconómico, lo que aumentaba su reconocimiento como miembros de la élite. En este sentido, los individuos que se reunían en el Casino eran la "flor y nata" de la colectividad española, relacionados con la élite mexicana y diferenciados del resto de españoles que vivían en México.

${ }^{11}$ AHEEM, c. 160, leg. 5-31, 22-9-1875; c. 160, leg. 5-36, 23-10-1875 у c. 162, leg. 3-23, 11-6-1876.

${ }^{12}$ La "deuda española" se refiere a una serie de tensiones financieras entre México y España que afectaron las relaciones diplomáticas entre ambos países entre 1836 y 1890 . Se relaciona con las reclamaciones que varios españoles interpusieron ante el gobierno mexicano para exigir el pago de la deuda contraída entre diversos prestamistas españoles y el gobierno durante las primeras décadas del siglo XIX. La falta de pago, por el estado de bancarrota y ruina en que se encontraba el país durante la primera mitad del siglo XIX y gran parte de la segunda-, dio lugar a la mediación de la Legación Española, que firmó varias convenciones con los gobiernos mexicanos para exigir la amortización de la deuda. Así, la deuda que México había reconocido como interna tomó el carácter de externa.

${ }^{13}$ Los desacuerdos sobre este tema fueron varios. Durante la presidencia de Lerdo de Tejada (1872-1876) se implementaron una serie de medidas tributarias que afectaban los ingresos de los empresarios peninsulares y eran percibidas de manera arbitraria por estos, pues se imponían gravámenes sobre el dinero en caja, libranzas, documentos privados y hasta sobre los muebles y alhajas que usaran las familias. (Llanos y Alcaraz, 1876: 309). Otro famoso desacuerdo ocurrió en 1879 con motivo del impuesto extraordinario sobre cada pieza de algodón y lana producidos en el país, lo que afectaba directamente a los industriales textiles del país, gran parte de los cuales eran de origen español y pertenecían al Casino Español. Estos individuos exigían la protección de la producción textil nacional en detrimento de la importación de efectos similares del extranjero, lo que ponía en jaque la política económica de Díaz para el desarrollo de las importaciones. "A la Cámara de Diputados", Benson Collection Rare Books, México, 20-5-1879 
pues en muchas ocasiones el segundo desconocía la autoridad del primero e iniciaba acciones por su propia cuenta. Aunque Enrique Muñiz era miembro del Casino Español, fue siempre favorable a la autoridad de la Legación como rectora indiscutible de los intereses de España y los españoles en el país. Su breve presencia al frente de La Voz de España había finalizado con su dimisión del cargo de director del periódico tan sólo un mes después de haber sido expulsado del Casino, con motivo de la publicación de unos artículos periodísticos que no habían sido del agrado de los miembros de la asociación españolista (Gutiérrez Hernández, 2004: 105) ${ }^{14}$. En este contexto se inserta la llegada de José Barbier a México.

José Barbier había nacido en Palma de Mallorca en 1822 y tuvo un importante papel como periodista, escritor y crítico teatral. Además, su carrera se encuentra vinculada al ejército español, al cual estaba afiliado desde 1840. Su ideología política estuvo siempre marcada por un progresismo político y estuvo relacionado con organizaciones demócratas y republicanas (Perelló Felani, 2003: 80-81; Fullana Puigserver, 1990: 54, $66)^{15}$. En 1857 se trasladó a Madrid, desde donde dirigió La Bandera del Pueblo (18691870), al comienzo del Sexenio Revolucionario. También fue autor de unos folletos político-sociales titulados "La bandera de la revolución", publicados en torno a 1870, de autoría colectiva. Fue uno de los republicanos más notables del distrito de Audiencia (Madrid) y miembro del Casino Ateneo Republicano de esta ciudad (Pérez Roldán, 2003: $69,120,250)^{16}$. No existen más datos de Barbier hasta su llegada a México, el 11 de abril de 1879. Una de sus primeras iniciativas en el país fue la fundación de la "Caja Popular Mexicana", una sociedad cooperativa de crédito y consumo que contaría con un semanario titulado La Cooperación y del que Barbier se convirtió en su director-gerente. Asimismo observamos su participación en la junta directiva de la Compañía Minera de Sierra Mojada ${ }^{17}$. Todo lo anterior revela la militancia de Barbier en el republicanismo

\footnotetext{
14 "Asesinatos de españoles. Sigue la impunidad", La Voz de España, 16-3-1880; Libro de Actas del Casino Español, vol. 1, ACEM, 18-3-1880.

${ }^{15}$ Creó el periódico semanal de literatura y artes El laurel literario (1842), que circulaba en las Islas Baleares y contó con 36 entregas; editó El Estudiantón (1843-44), periódico que reflejaba su ideología demócrata y del catolicismo social y publicó la obra de teatro Juana Souvry (1843), renovadora para la época al tratar la cuestión del divorcio. En 1854 publicó Fe y esperanza. Palma de los mártires dedicada a las víctimas de la causa del pueblo, en el glorioso alzamiento que tuvo lugar en Alicante el año 1844, que trataba sobre la fallida rebelión de Boné en esta ciudad, en la que él había participado de manera activa. Se trata de una obra de tono mesiánico en la que se pueden encontrar algunas de las ideas centrales del pensamiento demócrata-republicano y del socialismo. En Madrid fue redactor de la revista Ambos Continentes y escribió un folleto titulado "Cuestión de actualidad" (1864), dirigido al gobierno, los banqueros, los establecimientos de crédito y al comercio en general.

${ }^{16}$ En 1872, junto con otros miembros de la institución, firmó un documento dirigido a Pi y Margall en el que declaraban que la entrada del partido progresista radical en el poder no alteraba la postura del Partido Republicano Federal, que debía mantener su oposición al Gobierno. Ante la ambigüedad de Pi y Margall frente a esta demanda, Barbier y otros socios se dieron de baja del Casino.

${ }^{17}$ La Libertad, 13-4-1879; “Caja Popular mexicana”, El Siglo Diez y Nueve, 2-8-1879; “Compañía minera de Sierra Mojada", El Siglo Diez y Nueve, 1-11-1879.
} 
federal, en su vertiente revolucionaria, pues siempre tuvo el acento puesto en la capacidad autoorganizativa y los intereses de los sectores más populares.

Con la presencia de Barbier al frente de La Voz de España, una nueva característica comenzó a sobresalir dentro del periodismo español de la Ciudad de México. A este respecto, cabe señalar que durante el último tercio del siglo XIX esta prensa se caracterizó por la coexistencia de varias publicaciones que afirmaban ser representantes de la colonia española residente en la ciudad, como ya se ha comentado. Esta existencia dual no solía ocurrir de manera tranquila o pacífica, por múltiples motivos que fueron cambiando a lo largo del tiempo. A finales de la década de los 70 se debía a los antagonismos entre los partidarios del Casino Español y de la Legación, como se ha mencionado, aspecto que si bien no desapareció se iría diluyendo progresivamente en los años posteriores. En contraste, a partir de 1880 comenzaría a alcanzar mayor visibilidad en los periódicos de la colonia la oposición entre la defensa ideológico-política del republicanismo federal -por parte de Barbier- contra el republicanismo conservador, centralista y positivista que guiaba el pensamiento de Telesforo García, director del otro periódico español de la Ciudad de México, El Centinela Español (18791883). El origen de este último, fundado en diciembre de 1879 , se relaciona con el descontento que había provocado entre muchos socios del Casino Español la aparición de La Voz de España, auspiciado por la Legación. En consecuencia, Telesforo García renombrado miembro de la colectividad (Aguirre Gutiérrez, 1999: 201-207; Ledezma Martínez, 2012: 990-1000; Rosenzweig, 2003: 15-30)- fundó El Centinela Español y anunció su intención de ponerse al servicio de los intereses del Casino, lo cual fue recibido con entusiasmo por la Junta Directiva de esta institución ${ }^{18}$. Así, aunque las diferencias entre los periódicos de la colonia española evolucionaron con el paso del tiempo, las desavenencias se sostenían e insertaban en enemistades previas, lo cual permite comprender y complejizar la evolución social e ideológica de la colectividad española en el país.

La polémica principal entre José Barbier y Telesforo García en sus respectivos periódicos se originó como consecuencia de la celebración del aniversario de la independencia estadounidense, el 4 de julio de 1880. El festejo se llevó a cabo por iniciativa del periodista estadounidense Sr. Brannan, quien invitó a la celebración a diversos miembros de la prensa y la sociedad mexicana, entre los que se encontraban los dos periodistas españoles. En la celebración, Barbier protagonizó un brindis en el que ensalzaba la independencia estadounidense como precursora de las hispanoamericanas y situaba a las naciones americanas -por lo general regidas por regímenes republicanos federales- como ejemplo de la forma de gobierno que los países europeos deberían imitar, en oposición al republicanismo centralista de inspiración francesa. Así, Barbier

\footnotetext{
${ }^{18}$ Carta de R. del Valle, secretario del Casino Español, a Telesforo García, 28 noviembre 1879. Reproducida en: Libro de Actas del Casino Español, vol. 1, ACEM, 27-11-1879.
} 
deseaba que "Unidas entre sí todas estas Repúblicas, constituyan esa bella República universal federada, que dejando la más completa autonomía a cada grupo, grande y pequeño, constituyan la unidad verdadera dentro de la diversidad [...] Los pueblos mejor gobernados son los que menor cantidad de gobierno necesitan"19.

Telesforo García reaccionó con gran desagrado a estas palabras ${ }^{20}$. A este respecto, cabe resaltar que García había tomado parte en los trabajos de fundación del periódico La Libertad, en enero de 1878 -junto con Justo Sierra, Santiago Sierra, Francisco Cosmes, Jorge Hammeken y Eduardo Garay-, subsidiado por el gobierno y precursor de lo que en México se ha conocido como "liberalismo científico". Inspirado en las ideas de SaintSimon y Comte, este liberalismo se caracterizó por la defensa de una forma de gobierno republicana, de carácter centralista, con un poder ejecutivo fuerte y opuesto a las reformas sociales impulsadas desde abajo, así como la defensa de una reforma a la Constitución de 1857 -vigente en México en aquella época- que permitiese una jefatura de gobierno firme para lograr la consolidación de las instituciones. El liberalismo científico -conocido también como "liberalismo conservador"- se inspiró en la experiencia concreta de la III República Francesa y la I República Española, con Emilio Castelar como su principal referente (Hale, 2002: 50-53, 96) ${ }^{21}$. Es importante resaltar que durante su presidencia, Castelar había traicionado varios de los postulados del federalismo y defendido la república centralista. Además, había gobernado por medio de facultades extraordinarias y decretos para reprimir tanto a cantonalistas como carlistas, así como realizado un acercamiento con los grupos políticos más conservadores. Con estas medidas, Castelar creía garantizar la gobernabilidad de España durante la I República. Fueron estas ideas, entre otras, las que determinaron la enorme influencia del pensamiento de Emilio Castelar en México (Hale, 2002: 128-141; PosadaCarbó, 2002: 110-127; Rajo Serventich, 2007). Las diferencias acerca de la desigual manera de comprender la vía al republicanismo, dieron lugar a una agria polémica entre ambos periodistas en La Voz de España y El Centinela Español ${ }^{22}$.

La oposición entre la defensa del federalismo frente a un republicanismo de corte más conservador no se circunscribió únicamente a un debate ideológico sobre la República, sino que terminó teniendo implicaciones más amplias dentro del debate en torno al

\footnotetext{
19 “El Centinela Español”, La Voz de España, 13-7-1880.

${ }^{20}$ Un artículo en que se refleja el pensamiento de García acerca del federalismo y su oposición a esta forma de gobierno en: "La Federación en España”, El Centinela Español, 29-1-1880.

${ }^{21}$ La política científica acabó imponiéndose como programa del estado porfirista a partir de la década de los 90 , pero a fines de los 70 era aún una propuesta y una novedad.

${ }^{22}$ Para ver la polémica de manera detallada, véase: La Voz de España, 8-7-1880; "La Voz de España”, El Centinela Español, 11-7-1880; "El Centinela Español”, La Voz de España, 13-7-1880; "La Voz de España”, El Centinela Español, 15-7-1880; “El Centinela Español”, La Voz de España, 15-7-1880; "La Voz de España”, El Centinela Español, 18-7-1880; "El Centinela Español”, La Voz de España, 20-7-1880; "La Voz de España”, El Centinela Español, 22-7-1880.
} 
significado de "lo español" en México ${ }^{23}$. Así, en El Centinela Español Telesforo García artículo y aportó nuevos argumentos para la construcción de un discurso hispanista, tratando de romper con la asociación entre conservadurismo, monarquía y españolismo que existía en el discurso público mexicano (Pérez Vejo, 2008) ${ }^{24}$. Aunque, al igual que los conservadores, Telesforo García se apoyaba en el periodo de la conquista y dominio colonial para resaltar el valor de España en la historia, no lo hacía de manera acrítica pues se propuso defender la influencia cultural e histórica de España en México por medio del uso científico de la historia: el análisis de los datos ofrecidos al público por medio de su interpretación. Así, trataba de sensibilizar a un público mexicano liberal, del que él se consideraba parte (Mora, 2008; Hale, 2002: 62, 87) ${ }^{25}$. En este sentido, se puede comprender que la polémica a la que se ha aludido en el párrafo anterior, resultaba una ofensa tanto más grave para García cuanto que Barbier ponía en jaque la defensa de la influencia española en México, al poner como ejemplo para Hispanoamérica la independencia de Estados Unidos. Además, Barbier señalaba el periodo colonial como una época de la que no había por qué estar orgulloso. Esta polémica, que se manifestaría ulteriormente en otros artículos, revela una diversidad ideológica dentro de la colonia española y refleja un estadio diferente acerca del debate sobre "lo español" en México, antes protagonizado por los liberales y conservadores mexicanos. Por último, de lo que nos informa este debate es del probable desistimiento de la Legación en mantener su presencia y autoridad frente a los españoles por intermedio de la prensa, pues las ideas de Barbier -quien se había hecho cargo del otrora periódico impulsado por la Legacióndistaban de representar al gobierno de la Restauración (Mc Mahon, 1974: 111).

Al mediar la década de los 80 , el debate en torno a las formas de política contemporáneas que habrían de definir "lo español" tenía un triple flanco. Sumado al federalismo de Barbier y el centralismo de García, el debate implicó también a los periodistas monárquicos, como José Gándara de Velasco. Así, a raíz de una serie de

\footnotetext{
${ }^{23}$ Sobre la importancia de este debate en México, y en el conjunto de América Latina, a lo largo del siglo XIX, véase: Pérez Vejo, 2011.

${ }^{24}$ Tomás Pérez Vejo ha estudiado las visiones enfrentadas entre conservadores y liberales al construir una memoria colectiva que fuera el fundamento de la identidad nacional mexicana durante el periodo comprendido entre 1836 y 1867. Mientras los conservadores, en su mayoría favorables a la forma de gobierno monárquica- realizaban un balance positivo de la conquista y el consiguiente periodo de dominio colonial, para los liberales -sin duda republicanos en su mayor parte- la conquista era sinónimo de una época de oscuridad que se había prolongado durante casi tres siglos, por lo que la independencia habría puesto fin a este periodo de horror y barbarie. A partir de 1867 este último discurso fue el que triunfó, aunque en modo alguno fue un relato monolítico y no estuvo exento de polémicas y matices.

${ }^{25}$ El origen de este pensamiento liberal-científico de García, aplicado a la interpretación de lo español en México, se encuentra en su folleto España y los españoles en México (1877). Inspirado por las leyes generales del progreso y de la evolución, formuladas por Comte y Darwin, García usó la filosofía de la historia desde un punto de vista evolucionista, siguiendo la idea de que las naciones eran organismos vivientes que evolucionaban a lo largo del tiempo. Sus interpretaciones históricas acerca del origen de España y México, así como la relación que mediaba entre ellas, iban destinadas a descubrir un parentesco universal y cultural en relación con las nociones de raza latina.
} 
discursos pronunciados por Manuel Ruiz Zorrilla -líder del republicanismo español- a los que Barbier mostró adhesión, Gándara respondió alegando antiespañolismo y falta de patriotismo en su compatriota ${ }^{26}$. Estos términos también eran utilizados de manera común por Barbier para referirse a Gándara, a quien acusaba de ser, junto con su periódico, "malos españoles". Sirvan estos ejemplos como muestra de la diversidad político-ideológica de los representantes del periodismo español en la capital mexicana.

Con la intención de dar prioridad a sus negocios, en octubre de 1881 Telesforo García cedió la dirección de El Centinela Español a Ramón Elices Montes, quien lo dirigiría hasta su final, en abril de $1883^{27}$. Nacido en Baza (Granada) en 1844, Elices Montes había sido militar durante diecinueve años, llegando a alcanzar el grado de comandante. Su producción literaria, dramática, poética y política es abundantísima, por lo que una enumeración excedería los objetivos del presente texto. Vivió con entusiasmo el estallido de la Revolución de Septiembre, aunque sin destacarse en ninguna acción en particular. En 1869 publicó El progreso del ejército, folleto que le valió la recomendación de sus jefes en diversas instancias. En 1870 participó en la guerra de Cuba y volvió a España al año siguiente, al advenimiento de la I República. Esta forma de gobierno lo decepcionó profundamente, pues consideraba que se había traicionado en ella el ideal del republicanismo federal, por lo que comenzó a dirigir desde la Coruña El Adalid, donde atacaba la política de Emilio Castelar, así como el semanario satírico La Chispa Eléctrica, que defendía las mismas ideas. En 1878 escribió El Gobierno y el ejército de los pueblos libres, en el que defendía la República Federal como la mejor forma de gobierno, texto que remitió a los diferentes cuerpos del ejército. Como consecuencia de ello fue arrestado y encarcelado en la prisión de San Francisco (Madrid) y en el castillo de Santa Catalina (Cádiz), aunque finalmente resultó absuelto (Elices Montes, 1879; Soto y Corro, 1890: 3-17). Ana Rosa Suárez Argüello afirma que esta experiencia fue determinante en su decisión de abandonar España, lo que lo llevó primero a Francia y luego a México ${ }^{28}$.

Como podemos observar, Elices Montes compartía con Barbier algunas características biográficas, entre las que destaca - para el tema que nos ocupa- su militancia del lado del republicanismo federal. No obstante, esto no produjo una cercanía entre ambos periodistas y la distancia entre sus respectivos periódicos siguió siendo una realidad a lo largo del periodo. Aunque no se mantuvieron discusiones de tanta relevancia como las que existieron entre García y Barbier, pueden apuntarse algunas animadversiones mutuas. Probablemente la más ilustrativa sea la siguiente: a fines de junio de 1882, el

\footnotetext{
26 “Carta abierta”, El Pabellón Español, 30-5-1886.

27 “Al público y a la prensa”, El Centinela Español, 16 octubre 1881. Elices Montes había llegado a México a comienzos de ese año. "Llegada", El Centinela Español, 23-1-1881.

${ }^{28}$ Ana Rosa Suárez Argüello acaba de publicar una compilación de los artículos publicados por Ramón Elices Montes en El Centinela Español y El Pabellón Español. Además, la autora realiza un estudio introductorio de este personaje, donde explica de manera detallada la vida de Elices Montes antes de su llegada a México, así como el contexto histórico del país al que arribó (Suárez Argüello, 2018).
} 
periódico El Monitor Republicano propuso en sus páginas la conveniencia de que se introdujesen en México "libretas" para los obreros, donde los propietarios de fábricas y talleres o los directores de obras pudiesen anotar las faltas de estos, así como recomendar su conducta a patronos o jefes de taller de otros negocios, con el fin de acabar con los abusos de los trabajadores en materia de ausentismo o bajo rendimiento laboral ${ }^{29}$. Como respuesta a esta iniciativa, varios obreros publicaron una protesta en $E I$ Socialista. Barbier destacó por su participación en la junta del Congreso de los trabajadores, donde ocupó la tribuna, y propuso reunir cincuenta mil firmas contra la propuesta de El Monitor Republicano. La respuesta en El Centinela Español no se hizo esperar:

¿Un español llamado José Barbier y que edita un periódico que se llama La Voz de España fue el encargado de redactar la protesta de los obreros en la cual se habla de la época virreinal y de los feroces gachupines como acaban de ver nuestros lectores? ¿Y un español que edita un periódico, español también, cumple aquí su misión en la prensa azuzando a los obreros y promoviendo conflictos semejantes? [...] Nosotros hace tiempo que no tenemos con este español, ni con su periódico, ningún género de relaciones, pero [...] tenemos el deber de pedir [...] que se pruebe que el Monitor está equivocado, que no tiene sangre española, ni menos aún edita un periódico español en Méjico, quien promueve conflictos azuzando a los obreros [...] Si por desgracia, resultara cierto lo dicho por el Monitor, la colonia española se vería obligada a protestar contra la conducta de quien tan escandalosamente falta a sus deberes patrióticos y compromete el buen nombre de los mismos ${ }^{30}$

Elices Montes marcaba así su distancia y la de su periódico de cualquier demanda relacionada con la clase obrera y, de hecho, realizaba una defensa de los patronos, oponiéndose a Barbier y La Voz de España. Lo anterior relaciona a Elices Montes con el sector reformista del federalismo español.

\footnotetext{
29 "Las libretas de obreros", El Monitor Republicano, 28-6-1882.

30 “iPícaros gachupines!”, El Centinela Español, 7-7-1882.
} 


\section{La relación con el gobierno de Porfirio Díaz}

Los gobiernos de Porfirio Díaz (1876-1880, 1884-1911) y Manuel González (1880-1884) estuvieron regidos por la Constitución de 1857, que establecía que México era una República Federal. No obstante, gran parte de la praxis política de este periodo se caracterizó por una progresiva centralización del aparato estatal, un gradual abandono de los principios del liberalismo -supeditados a la búsqueda de la estabilidad y la paz para el país- y una concentración del poder en la figura de Porfirio Díaz como árbitro político. Así, pese a la vigencia de la Constitución, cada vez fue ganando más fuerza lo que se ha conocido como "liberalismo patriarcal” (Garner, 2003: 103-138). Aunque estas prácticas políticas comenzaron a ganar fuerza a partir de 1884, no hemos encontrado datos concluyentes de la postura de José Barbier a este respecto, aunque sabemos que sus ideas se adscribían a la corriente más radical del federalismo y estaban muy alejadas del ideario del "liberalismo científico" en que se apoyó el régimen de Díaz. No obstante, Barbier no mantuvo nunca una actitud de activa oposición al gobierno, si bien denunció en reiteradas ocasiones los encarcelamientos a periodistas que practicó el régimen con motivo de disidencias políticas e ideológicas ${ }^{31}$.

Por su parte, Ramón Elices Montes fue receloso con algunos aspectos del gobierno mexicano durante los últimos años del régimen de González, como el sistema de contratación de inmigrantes (Mc Mahon, 1974: 121) o la prensa subvencionada por el gobierno (Elices Montes, 1885: 223-224). No obstante, tras su vuelta a España -a finales de 1884- publicó Cuatro años en México (1885), un libro prologado por Emilio Castelar en el que alababa los adelantos industriales, comerciales y de transporte desarrollados en México. El libro, cuyo objetivo era dar a conocer el país en España, pues su autor afirmaba que la imagen que se tenía de él era muy errónea, promovía una imagen muy favorable de México. Además, denunciaba la falta de interés de España en la política hispanoamericana y la necesidad de que el gobierno de la Restauración se implicase de manera más activa en las relaciones bilaterales con México (Elices Montes, 1885: 372). Así, el periodista actuó como embajador oficioso del régimen porfiriano, promoviendo una imagen favorable del país de acuerdo a la que el propio Díaz estuvo interesado en exportar al ámbito internacional desde fines de 1884. En este sentido, Elices Montes se acercaba al comportamiento que caracterizaría a la colonia española a partir de la

\footnotetext{
${ }^{31}$ La libertad de prensa en México se vio profundamente afectada tras la reforma del artículo 7 constitucional, que suponía la supresión de los jurados populares para los delitos de imprenta y su traslado a la jurisdicción de los tribunales de orden común. Así, se buscaba perseguir el periodismo independiente por la vía legal, permitiendo al gobierno frenar las expresiones disidentes. La persecución de la prensa, implementada mediante la reforma del Art. 7 y aplicada a partir de 1885, fue uno de los elementos principales utilizados para acallar la oposición y fortalecer el sistema político del Porfiriato, en un contexto de falta de independencia entre el poder ejecutivo y judicial (Gantús, 2009: 279-336).
} 
segunda mitad de los años 80, marcado por el acercamiento entre la élite de la colectividad -reunida en torno al Casino Español-y el gobierno de Díaz.

A partir de la segunda presidencia de Díaz (1884-1888), comenzó el proceso de fortalecimiento del régimen, ligado al acallamiento de la oposición política ${ }^{32}$, la pacificación del país, la expansión de las comunicaciones, el desarrollo del libre comercio, la apertura del régimen al ámbito internacional y la entrada de inversiones para promover la industria nacional, entre otras cuestiones (Garner, 2003: 139-191). En relación con este último aspecto, cabe señalar el establecimiento de acuerdos ventajosos con capitalistas e industriales españoles residentes en México, quienes en años anteriores habían acumulado importantes fortunas, por lo que este periodo destaca por la creciente asociación entre la élite española y el gobierno mexicano, al compás del desarrollo capitalista en México ${ }^{33}$. Los aspectos anteriores modificarían la manera en que se condujo tanto la colonia española residente en la capital mexicana como los periodistas de este origen que actuaron como sus voceros, así como la relación que establecieron con el gobierno de Díaz.

Para ilustrar este periodo resulta fundamental la figura de José Román Leal, que en agosto de 1885 se convirtió en director de El Pabellón Español, un periódico que dos años antes se había sumado a la lista de publicaciones españolas en la capital mexicana ${ }^{34}$. Leal era un jurisconsulto muy conocido por su actividad política y periodística en la isla de Cuba. Había llegado a México a mediados de 1884 y se encontraba en torno a los setenta años cuando entró a dirigir El Pabellón Español ${ }^{35}$. En 1873, durante el desarrollo de la Guerra de los Diez Años en Cuba (1868-1878) y en el contexto de la proclamación de la I República, había fundado en La Habana La Legalidad, periódico republicano federalista de inspiración oficial (Roldán de Montaud, 1992: 261, 273). Tras la Paz de Zanjón (1878), que puso fin a la contienda, Leal-junto a otros-fundó el efímero Partido Liberal Nacional (PLN), una escisión del Partido Liberal (PL) formado por demócratas peninsulares que apoyaban los principios del PRF (Roldán de Montaud,

\footnotetext{
${ }^{32}$ La ausencia de una oposición fuerte al gobierno, sobre todo por parte de los liberales, aunque no así de los conservadores, representaba la culminación de las políticas de "reconciliación" del Porfiriato, emprendidas sobre todo entre 1884-1888 (Hale, 2002: 166-173).

${ }^{33}$ El capital y las propiedades de españoles tuvieron una gran importancia en el proceso formativo de la sociedad capitalista mexicana. Como explica Mario Cerutti, los protagonistas de este proceso eran individuos que habían adquirido experiencia empresarial en actividades comerciales desarrolladas en México, lo cual les permitió acumular un capital que más tarde volcarían en importantes inversiones, muchas de ellas ligadas al gobierno (Cerutti, 1995).

${ }^{34}$ Se creó en julio de 1883. Su fundador y director, Ramón Elices Montes, afirmó que era continuación de El Centinela Español. “Al público y a la prensa”, El Pabellón Español, 1 julio 1883.

35 “A los suscritores”, El Pabellón Español, 31-7-1885; “Fotografías instantáneas”, El Siglo XIX, 20-6-1892.
} 
2000: 127; Casanovas, 2000: 148-149) ${ }^{36}$. Por medio de esta plataforma política se exigió el cumplimiento de una política radical reformista que garantizase en Cuba las mismas libertades de que gozaba el resto de España desde la Constitución de $1876^{37}$.

Leal fue abogado, catedrático y rector de la Universidad de la Habana. En 1879 fue elegido Senador del Reino por la Sociedad Económica de Amigos del País de La Habana ${ }^{38}$, que desde la década de los 60 era un centro favorable a la introducción de reformas políticas y económicas que agilizasen el intercambio comercial de productos cubanos con España y otras potencias. Para ello, la Sociedad había buscado el respaldo de las organizaciones de trabajadores, muy permeadas por los ideales federalistas (Casanovas, 2000: 89-90). En 1882 abandonó el Senado para fundar La Verdad, un periódico cubano que abogaba por la creación de un partido democrático monárquico (Izquierda Dinástica), que con un programa de acción nacional predicaba la igualdad política entre provincias, la descentralización administrativa y la abolición del patronato (Roldán de Montaud, 2000: 221-235) ${ }^{39}$. Como se puede observar, Leal tuvo una larga trayectoria dentro de la corriente del republicanismo federal, adscrito al sector más reformista. Estos datos son importantes para observar su evolución ulterior.

En El Pabellón Español, José Román Leal abrazó los proyectos impulsados por Porfirio Díaz para la modernización del país, acercando los intereses de los industriales y comerciantes españoles con los del gobierno ${ }^{40}$. Afirmaba que la colonia española se identificaba con el rumbo de la nación -orden, seguridad, integridad de la ley, garantía de trabajo, libertad y paz-y respaldaba la necesidad de México de obtener crédito para el impulso de la industria ${ }^{41}$. Así, Leal se convirtió en vocero e intérprete de una colonia

\footnotetext{
${ }^{36}$ Lo que diferenciaba al PLN del PL era "el sentido de la política cubana con relación a la peninsular": mientras el PL defendía una dirección y tendencia más locales, el PLN se movía en una esfera nacional, pues consideraban que el PL no garantizaba la integridad nacional.

${ }^{37}$ Derecho de asociación, libertad de imprenta y libertad de enseñanza, fundamentalmente.

${ }^{38}$ En 1879-1880 y 1880-1881. Véase: “Discurso de Contestación al discurso de la Corona”, Diario de las Sesiones de Cortes, 1881, pp. 83-93 y "Expediente personal del Senador D. José Román Leal, por la Sociedad Económica de La Habana", ASE, ES.28079.HIS-0244-01 (en línea: http://www.senado.es/web/conocersenado/senadohistoria/senado18341923/senadores/fichasenador/ index.html?id1=1567)

${ }^{39}$ La escasa representación en el Senado de los liberales autonomistas, en comparación con la UC, llevó a la necesidad de asociarse con grupos peninsulares que hiciesen suya la causa de los autonomistas. Roldán de Montaud realiza un análisis minucioso de las implicaciones que tenía la relación entre los diferentes partidos políticos cubanos y peninsulares.

${ }^{40}$ En mayo de 1885 Leal había propuesto a Díaz un proyecto de colonización progresiva en consonancia con la política impulsada desde la Secretaría de Fomento. Véase: Carta de Leal a Díaz, 2-5-1885, APD, c11, leg. 10, doc. 5164; Carta de Díaz a Leal, 2-5-1885, APD, c-11, leg. 10, doc. 5165; Carta de Leal a Díaz, 12-5-1885, APD, c-11, leg. 10, doc. 5195; Carta de Leal a Díaz, 14-5-1885, APD, c-11, leg. 10, doc. 5199; Carta de Díaz a Leal, 15-5-1885, APD, c-11, leg. 10, doc. 5196; Carta de Leal a Díaz, 27-5-1885, APD, c-11, leg. 10, doc. 5219; Carta de Díaz a Leal, 15-5-1885, APD, c-11, leg. 10, doc. 5220.

41 “México, su gobierno y la colonia española”, El Pabellón Español, 7 agosto 1885; “Problema único”, El Pabellón Español, 9 agosto 1885. Leal a P. Díaz, 27-5-1885.
} 
española que, cada vez más, deseaba participar en la obra de crecimiento económico proyectada por Díaz ${ }^{42}$. El nuevo director dedicaría gran parte de su trabajo en México a la consagración de este fin y adivinó que la única posibilidad de alcanzarlo era posponiendo sus demandas federalistas y democráticas para abrazar la defensa de un gobierno fuerte y centralista, como el que encarnaba Porfirio Díaz ${ }^{43}$. En realidad, estos eran los presupuestos de la "política científica" defendida en La Libertad, que fue el sostén ideológico del régimen porfirista: el gobierno autoritario sería el preludio de un régimen liberal auténtico, que aseguraría la renovación de las instituciones y la armonía entre la constitución escrita y la realidad, cuando las condiciones del país lo permitiesen (Hale, 2002: 29).

Aunque Leal fue director de El Pabellón Español tan sólo por unos meses ${ }^{44}$, más tarde fundaría el que sin duda fue su periódico insignia, La Nueva Iberia (1887-1888). El contexto de creación de esta publicación se inscribe en un periodo sumamente conflictivo para la colonia española de la capital mexicana. El triunfo de Juan Llamedo en las elecciones para la Junta Directiva del Casino Español en 1887 -que ganó por una diferencia de 16 votos a la candidatura de Pedro Suinaga, representante de una vieja generación de españoles que durante años había acaparado la representación de la colectividad- produjo una fuerte escisión en la colonia. En parte, el conflicto tenía una dimensión generacional y suponía la entrada a puestos de gobierno de la asociación españolista de un grupo de jóvenes empresarios, que relegaba a un segundo plano a los miembros más antiguos de la sociedad. No obstante, la disputa tenía también una vertiente más política, pues Llamedo y su camarilla eran conocidos por su excesiva afinidad con el gobierno de Díaz. Tras el resultado de las elecciones, se afirmó que el Casino Español corría el peligro de conocerse como "Casino Tuxtepeco", en alusión a la Revolución de Tuxtepec (1876) que había llevado a Díaz al poder (Gutiérrez Hernández, 2004: 109-111). Además, El Pabellón Español aseveró que había habido fraude en la celebración de las elecciones ${ }^{45}$ e implementó una dura campaña de prensa en contra de

\footnotetext{
${ }^{42}$ Además, su interés en que El Pabellón Español fuese afín al gobierno se muestra en el envío a Díaz de ejemplares de la publicación. En esta correspondencia Díaz indica a Leal que, en caso de ser necesario, le hará las indicaciones pertinentes. Véase: Cartas entre Leal y Díaz, 24-10-1885, APD, c-20, leg. 10, docs. 9672, 9673, 9674 y Carta de Díaz a Leal, 24-10-1885, APD, c-3, leg. 41, tomo 5 folio 15. Además, cabe destacar que al poco de su llegada a México Leal solicitó una audiencia con Díaz y le indicó que se ponía a su disposición para cualquier servicio que considerase necesario. Carta de Leal a Díaz, 13-10-1884, APD, c-1, leg. 9, doc. 254.

43 "Fundamentos políticos”, El Pabellón Español, 11-10-1885.

${ }^{44}$ Entre 2-8-1885 y 8-9-1885 y, de manera conjunta con Gándara de Velasco, entre 10-11-1885 y 10-31886.

45 “Casino Español”, alcance al número 647, El Pabellón Español, 25-12-1886; "El Casino Español”, El Pabellón. Sobre este conflicto, véase también: "El Casino Español”, La Voz de España, 30-12-1886; “A la colonia española", La Voz de España, 31-12-1886; "La madre del borrego", La Voz de España, 1-1-1887; “El Pabellón Español”, La Voz de España, 5-1-1887; “El Casino Español”, La Voz de España, 6-1-1887.
} 
la victoria de Llamedo ${ }^{46}$. Todo lo anterior dio lugar a la creación de un periódico que fuese la voz sin ambages del Casino Español, por lo que se fundó La Nueva Iberia, bajo la dirección de José Román Leal.

La nueva publicación se identificaba con los intereses de los industriales, comerciantes y financieros españoles, quienes deseaban el desarrollo económico de México para impulsar sus negocios con facilidades y garantías. Así, como en El Pabellón Español, Leal aplaudía la necesidad de desarrollar el crédito como requisito para el progreso del país y aprobaba la reelección presidencial para 1888 como garantía de paz ${ }^{47}$. El periódico se burlaba de las publicaciones que cuestionaban la libertad de expresión y opinaba que, por el contrario, el deber de la prensa era estar al servicio de un mandatario que sirviera a la sociedad, como Porfirio Díaz ${ }^{48}$. En consecuencia, La Nueva Iberia fue un órgano gubernista al servicio de una nueva generación de hombres de negocios que acababan de ganar la Directiva del Casino Español y estaban interesados en obtener concesiones del gobierno. A su vez, este deseaba impulsar el desarrollo de México con el capital de los empresarios residentes en el país, así como el de las naciones extranjeras.

La contribución de Leal a la obra política del Porfiriato no finalizaba con la fundación de un periódico afín al gobierno, pues también colaboró activamente en la propagación de una imagen favorable de México, tanto dentro como fuera del país, que convenciese a los futuros acreedores del progreso nacional y situase al país en el concierto de las naciones modernas. Con este propósito escribió México Constitucional (1886) y Proceso de la historia (1890). La primera obra consigna el progreso de México a la luz de los éxitos del liberalismo y su victoria definitiva sobre los conservadores. La segunda, publicada por la Secretaría de Fomento, analiza el Mensaje Presidencial de 1889 con el objetivo de ser remitido a los gobiernos extranjeros y concluye situando a México como la República Federal modelo que debía servir como ejemplo al resto de países

\footnotetext{
46 “El Casino Español”, El Pabellón Español, 4-1-1887; “Seis u ocho y...”, El Pabellón Español, 5-1-1887; “El Casino Español”, El Pabellón Español, 13-1-1887.

47 "El comercio y la industria”, La Nueva Iberia, 11-3-1887; “El empréstito mexicano”, La Nueva Iberia, 183-1887; "La reforma constitucional y la confianza", La Nueva Iberia, 26-4-1887.

48 “Los mártires de la tiranía”, La Nueva Iberia, 16 abril 1887; “A la Guardia vieja del periodismo”, La Nueva Iberia, 19-4-1887 y 21-4-1887. Igual que en El Pabellón Español, Leal tenía correspondencia directa con Díaz, a quien enviaba los ejemplares de su periódico en los que avalaba la labor de gobierno y la figura del presidente. Asimismo, tras el cierre del periódico, en diciembre de 1888, Leal escribió a Díaz para comunicarle que no obstante seguiría escribiendo en las columnas de otros periódicos de la capital, para lo cual se ponía a sus órdenes en lo que fuese necesario. Carta de Leal a Díaz, 15-11-1888, APD, c-22, leg. 13, doc. 10798; Carta de Díaz a Leal, 17-11-1888, APD, c-22, leg. 13, doc. 10799; Carta de Leal a Díaz, 1911-1888, APD, c-24, leg. 13, doc. 11914; Carta de Leal a Díaz, 12-1-1889, APD, c-1, leg. 14, doc. 455; Carta de Díaz a Leal, 18-1-1889, APD, c-1, leg. 14, doc. 456.
} 
occidentales del orbe. Por último, Leal colaboraba en periódicos de Nueva York encomiando los progresos de Díaz ${ }^{49}$.

El viraje ideológico experimentado por José Román Leal tras su arribo a México le valió sendas críticas por parte de sus correligionarios. Así, La Voz de España publicó una colaboración anónima en la que su redactor se refería a Leal como "nuestro antiguo correligionario", quien había bajado muchos grados su pujanza autonomista y democrática ${ }^{50}$. Por su parte, El Pabellón Español publicó un artículo dirigido a Leal en el que le decía “¡Vd. vendido!...El jefe de la libertad de un pueblo se convierte en el miserable lansquenete de un despotismo salvaje" ${ }^{51}$.

El viraje advertido en José Román Leal entre su militancia española y su posicionamiento político en México es también reconocible en Ramón Elices Montes, quien tras su arribo a España publicó un libro laudatorio del régimen de Díaz, el cual estuvo prologado por uno de los referentes intelectuales del Porfiriato, Emilio Castelar, como se ha comentado en páginas anteriores. Respecto de este giro político o militante entre estos periodistas, cabría arrojar algunas hipótesis. En primer lugar, el posible desencanto con las esperanzas depositadas en la experiencia de la I República Española; en segundo lugar, el aprovechamiento del momento político por el que pasaba la relación entre los españoles ubicados en un sector socioeconómico privilegiado y el gobierno de Porfirio Díaz, sobre todo a partir de la segunda mitad de la década de 1880; por último, una posible transformación del pensamiento político de estos individuos que, reorientado hacia un mayor conservadurismo, tenía muchas similitudes con la propia evolución del pensamiento castelariano. Posiblemente, la combinación de todos o algunos de estos aspectos sea la respuesta más probable.

\section{Conclusiones}

En este artículo se han presentado algunos periodistas adscritos al republicanismo federal en los periódicos de la colonia española en la capital mexicana, con la intención de poner de relevancia que algunas de las características que dieron forma a estas publicaciones tuvieron mucho que ver con aspectos de configuración interna de la colonia y con los cambios políticos acaecidos en España. También se ha observado que, aunque el fracaso de la primera experiencia republicana marcó la emigración o el exilio

\footnotetext{
${ }^{49}$ Carta de Leal a Díaz, 6-8-1889, APD, c. 17, leg. 14, doc. 8482; Carta de Leal a Díaz, 19-8-1889, APD, c. 17, leg. 14 , doc. 8481.

50 "Carta de España”, La Voz de España, 9-12-1885.

51 "Epístola de agua fuerte”, El Pabellón Español, 11-2-1887. A partir de mayo del mismo año las ofensas y burlas a Leal en El Pabellón Español aparecían en el apartado "Casos y Cosas", donde el apelativo de "Don Estólido" hacía referencia al director de La Nueva Iberia.
} 
de varios de sus partidarios, su convivencia en México no estuvo marcada por el acercamiento mutuo. Pese a compartir la idea de que el federalismo era la mejor forma de gobierno, estos individuos disentían en aspectos fundamentales, relacionados con la clase trabajadora -frente a la patronal-, su dispar relación con el gobierno mexicano o su mayor o menor cercanía con los intereses de la colonia española reunida en torno al Casino Español; todo lo cual los distanciaba entre sí. Por otro lado, desde sus periódicos, estos individuos trataron de influir en el debate nacional en torno al significado de "lo español", tratando de eliminar la asociación que históricamente existía en México entre "españolismo", "monarquía", "régimen colonial" y "opresión". Por el contrario, la experiencia de la I República y los numerosos episodios cantonalistas que ocurrieron en su seno -finalmente reprimidos y fracasados- sirvieron para demostrar que España también podía ser sinónimo de federalismo y, a partir de ahí, buscar un acercamiento con discursos y realidades mexicanas y/o americanas. Por último, se ha podido observar que los republicanos federales -siendo el caso paradigmático el de José Román Lealfueron comprensivos, aunque con distintos niveles de compromiso, con el régimen de Porfirio Díaz, con el cual colaboraron activamente.

\section{Archivos}

ACEM - Archivo del Casino Español de México

AHEEM - Archivo Histórico de la Embajada de España en México

AHN - Archivo Histórico Nacional, España

APD - Archivo de Porfirio Díaz, México

ASE - Archivo del Senado de España

\section{Referencias bibliográficas}

AGUIRRE GUTIÉRREZ, R. (1999): “Telésforo García (1844-1918), un indiano bienhechor de Bustriguado-Roiz, olvidado", en Altamira: Revista del Centro de Estudios Montañeses, no 55, pp. 201-208.

BIAGINI, H. (1995): Intelectuales y políticos españoles a comienzos de la inmigración masiva, Buenos Aires, Centro Editor de América Latina. 
CASANOVAS, J. (2000): iO pan, o plomo! Los trabajadores urbanos y el colonialismo español en Cuba, 1850-1898, Madrid, Siglo Veintiuno.

CERUTTI, M. (1995): Empresarios españoles y sociedad capitalista (1840-1920), Gijón, Archivo de Indianos.

DEVOTO, F. (2003): Historia de la inmigración en la Argentina, Buenos Aires, Sudamericana.

ELICES MONTES, R. (1885): Cuatro años en Méjico. Memorias íntimas de un periodista español, Madrid, Imprenta de la viuda de J. M Pérez.

- (1879): El gobierno y el ejército de los pueblos libres, con la sentencia absolutoria y la biografía del Autor, Madrid, Imprenta de Aurelio J. Alaría.

FULLANA PUIGSERVER, P. (1990): El Catolicisme Social a Mallorca (1877-1902), Barcelona, Publicacions de l'Abadia de Montserrat.

GANTÚS, F. (2009): Caricatura y poder político. Crítica, censura y represión en la ciudad de México, 1876-1888, México, El Colegio de México-Instituto Mora.

GARCíA, Telesforo (1877): España y los españoles en México, México, Santiago Sierra Tipógrafo.

GARNER, P. (2003): Porfirio Díaz. Del héroe al dictador: una biografía política, México, Planeta.

GUTIÉRREZ HeRNÁNDEZ, A. (2004): Casino Español de México: 140 años de historia, México, Editorial Porrúa.

HALE, C.A. (2002): La transformación del liberalismo en México a fines del siglo XIX, México, Fondo de Cultura Económica.

- (2002): "Emilio Castelar and Mexico", en JAKSIC (ed.): The Political Power of the Word. Press and Oratory in Nineteenth-Century Latin America, Londres, Universidad de Londres- Instituto de Estudios Latinoamericanos, pp. 128-141.

HERRERA LASSO, A. L. (1998): “Una élite dentro de la élite: el Casino Español de México entre el Porfiriato y la revolución (1875-1915)", en Secuencia, no 42, pp. 177-205.

LEDEZMA MARTÍNEZ, J. M. (2013): "Telésforo García: un emigrante montañés en el Porfiriato", en Actas del Congreso Internacional "América Latina: La autonomía de una región", organizado por el Consejo Español de Estudios Iberoamericanos y la Facultad de Ciencias Políticas y Sociología de la Universidad Complutense de Madrid, en Madrid el 29 y 30 de noviembre de 2012, pp.990-1000. 
LIDA, C.E. (1994): “El perfil de una inmigración: 1821-1939”, en LIDA, C.E. (coord.): Una inmigración privilegiada. Comerciantes, empresarios y profesionales españoles en México, Madrid, Alianza América.

LLANOS Y ALCARAZ, A. (1876): No vengáis a América. Libro dedicado a los pueblos europeos, México, Imprenta de La Colonia Española.

Mc MAHON, T.J. (1974): The Spanish Immigrant Community in Mexico City during the Porfiriato, 1876-1911, Indiana, Notre Dame University.

MORA, P. (2008): "Telesforo García: articulista y polemista en El Centinela Español", en MORA, P. y MIQUEL, A. (comps.), Españoles en el periodismo mexicano. Siglos XIX y $X X$, México, Universidad Nacional Autónoma de México-Instituto de Investigaciones Bibliográficas-Universidad Autónoma del Estado de Morelos pp. 123-136.

MOYA, J.C. (2004): Primos y extranjeros: la inmigración española en Buenos Aires (18501930), Buenos Aires, Emecé.

PERELLÓ FELANI, F. (coord.) (2003): Diccionari del teatre a les Illes Balears, Palma, Govern de les Illes Balears. Conselleria d’Educació i Cultura.

PÉREZ ROLDÁN, M.C. (2003): Bases sociales del republicanismo madrileño (1868-1874), Madrid, Universidad Complutense de Madrid, tesis de doctorado.

PÉREZ VEJO, T. (coord.) (2011): Enemigos íntimos. España, lo español y los españoles en la configuración nacional hispanoamericana 1810-1910, México, El Colegio de México.

- (2008): España en el debate público mexicano, 1836-1867. Aportaciones para una historia de la nación, México, El Colegio de México.

PI-SUÑER LLORENS, A. (2006), La deuda española en México: diplomacia y política en torno a un problema financiero, 1821-1890, México, El Colegio de MéxicoUniversidad Nacional Autónoma de México.

- (1994): "Negocios y política a mediados del siglo XIX", en LIDA, C.E. (comp.): Una inmigración privilegiada. Comerciantes, empresarios y profesionales españoles en México, Madrid, Alianza América, pp. 75-96.

PI-SUÑER LLORENS, A. y SÁNCHEZ ANDRÉS, A. (2001): Una historia de encuentros y desencuentros: México y España en el siglo XIX, México, Secretaría de Relaciones Internacionales.

POSADA-CARBÓ, E. (2002): “Emilio Castelar: república, liberalismo y el poder de la oratoria", en JAKSIC (ed.): The Political Power of the Word. Press and Oratory in 
Nineteenth-Century Latin America, Londres, Universidad de Londres- Instituto de Estudios Latinoamericanos, pp. 110-127.

RAJO SERVENTICH, A. (2007): Emilio Castelar en México. Su influencia en la opinión pública mexicana a través de El monitor republicano, México, Universidad Autónoma de la Ciudad de México.

RIVADULLA BARRIENTOS, D. (1992): “El exilio republicano", en: RIVADULLA, NAVARRO y BERRUEZO: El exilio español en América en el siglo XIX, Madrid, Editorial Mapfre, pp. 309-390.

ROLDÁN DE MONTAUD, I. (2000): La Restauración en Cuba. El fracaso de un proceso reformista, Madrid, Consejo Superior de Investigaciones Científicas.

- (1992): "La I República y Cuba" en Revista Complutense de Historia de América, no 18, pp. 257-279

ROSENZWEIG, G. (comp.) (2003): Un liberal español en el México porfiriano. Cartas de Telesforo García a Emilio Castelar, México, Conaculta.

SOTO Y CORRO, C. (de) (1890): Americanistas ilustres, Excmo. e Ilmo. Sr. Don Ramón Elices Montes: apuntes biográficos, Madrid, Imprenta de José Perales.

SUÁREZ ARGÜELLO, A. R. (2018): Ramón Elices Montes: Redactor de El Centinela Español y El Pabellón Español, México, Instituto de Investigaciones Dr. José Maria Luis Mora.

VIEYRA SÁNCHEZ, L. (2014): Adolfo Llanos y Alcaraz. El ejercicio periodístico como expresión y poder de un sector hispano en México, México, Universidad Nacional Autónoma de México, tesis de doctorado.

VILAR, J.B. (2012): La España del exilio. Las emigraciones políticas españolas en los siglos $X I X$ y $X X$, Madrid, Sintesis. 